\title{
25 Research Square \\ Effects of Exenatide on Blood Coagulation and \\ Platelet Aggregation in Patients with Type 2 \\ Diabetes
}

\section{Yaqin Zhang}

First Affiliated Hospital of Anhui Medical University https://orcid.org/0000-0002-9538-2173

\section{Ruofei Chen}

First Affiliated Hospital of Anhui Medical University

Yangyang Jia

First Affiliated Hospital of Anhui Medical University

Zongwen Shuai ( $\square$ shuaizongwen@ahmu.edu.cn )

First Affiliated Hospital of Anhui Medical University

Mingwei Chen

First Affiliated Hospital of Anhui Medical University

Original investigation

Keywords: Glucagon-like peptide-1, Type 2 diabetes mellitus, Exenatide, Platelet activation, Thrombosis

Posted Date: March 16th, 2021

DOI: https://doi.org/10.21203/rs.3.rs-292137/v1

License: (9) This work is licensed under a Creative Commons Attribution 4.0 International License.

Read Full License 


\section{Abstract}

Background: To explore the effect of glucagon-like peptide-1 receptor (GLP-1R) agonist exenatide on blood coagulation function and platelet aggregation function in patients with type 2 diabetes mellitus (T2DM).

Method: Thirty patients with newly diagnosed T2DM were enrolled as the case group, and 30 healthy people with matching age and sex were selected as the control group. Patients in the case group received exenatide treatment for 8 weeks. Collect the general clinical data and biochemical indicators of the patients in the case group before and after 8 weeks of exenatide treatment and the control subjects, and detect their peripheral blood platelet count $\left(\times 10^{12} \mathrm{~g} / \mathrm{L}\right)$, plasma prothrombin time $(\mathrm{PT}, \mathrm{s})$, prothrombin time activity (PTA, \%), activated partial thromboplastin time (APTT, s), international normalized ratio $(I N R)$, fibrinogen (FIB, $g / L)$, plasma thrombin time $(T T, s)$, Fibrin degradation products (FDP, $\mu \mathrm{g} / \mathrm{mL})$, Ddimer (DD, $\mu \mathrm{g} / \mathrm{mL}$ ), nitric oxide (NO, $\mu \mathrm{mol} / \mathrm{L}), \mathrm{CD} 62 \mathrm{p}(\%)$, platelet activation complex-1 (PAC-1, \%) and platelet aggregation induced by collagen, epinephrine, arachidonic acid (AA, \%), and adenosine diphosphate (ADP, \%).

Results: There was no significant difference in platelet count, PLT, PT, PTA, APTT, TT, INR, FDP, DD between the case group and the control group; the FIB, CD62p, PAC-1, platelet aggregation rates of the case group (EPI 87.23 $\pm 6.84, A D P$ 87.51 $\pm 9.21, A A 90.17 \pm 3.19)$ is higher than normal control group (EPI $82.15 \pm 5.37$, ADP $82.38 \pm 6.42, A A 83.41 \pm 6.17, P \otimes 0.05)$, NO level is lower than normal control group (68.1 \pm 14.7 vs. $79.4 \pm 11.2, P<0.05$ ); After 8 weeks of exenatide treatment in the case group, CD62p, PAC-1, and platelet aggregation rates were lower than before (EPI: $81.62 \pm 9.02$ vs. $87.23 \pm 6.84$, AA: $84.62 \pm 7.12$ vs. $90.17 \pm 3.19, P \otimes 0.05)$, the level of NO was higher than before (89.6 \pm 15.8 vs. $68.1 \pm 14.7)$; Pearson correlation analysis showed that the changes in platelet aggregation rates $(\triangle \mathrm{EPI}, \triangle \mathrm{AA})$ of patients in the case group after 8 weeks of exenatide treatment were positively correlated with the changes in body mass index $\left(\mathrm{BMl}, \mathrm{kg} / \mathrm{m}^{2}\right)$, waist circumference $(\mathrm{cm})$, weight $(\mathrm{kg})$, total cholesterol $(\mathrm{TCH}, \mathrm{mmol} / \mathrm{L})$, triglycerides ( $T G, \mathrm{mmol} / \mathrm{L}$ ), low-density lipoprotein (LDL-C, mmol/L), fasting plasma glucose (FPG, $\mathrm{mmol} / \mathrm{L})$, Hemoglobin A1c (HbA1c, \%), CD62p, PAC-1 $(P<0.05)$, and negatively correlated with the change of high density lipoprotein $(\mathrm{HDL}-\mathrm{C}, \mathrm{mmol} / \mathrm{L})$ and $\mathrm{NO}(P<0.05)$. Multiple linear regression analysis showed that the changes of NO, CD62p and PAC-1 were independent risk factors affecting the changes of platelet aggregation rates.

Conclusions: The GLP-1R agonist exenatide can inhibit the activation state of platelets in patients with T2DM, reduce the platelet aggregation rate, and inhibit thrombosis, which is beneficial to reduce the risk of cardiovascular events.

\section{Background}

Type 2 diabetes mellitus (T2DM) is a progressive metabolic disease characterized by chronic hyperglycemia. High glucose toxicity, lipotoxicity and insulin resistance are components of the 
pathophysiology of T2DM, which mainly affect the integrity of the blood vessel wall, leading to increased inflammation, endothelial dysfunction, enhanced platelet aggregation and coagulation factor dysfunction[1-3]. In addition to causing microvascular complications (retinopathy, nephropathy, and neuropathy), this complicated pathophysiology also leads to a 2-4 times increase in the risk of thrombosis and cardiovascular disease (CVD) in patients with T2DM [4, 5]. The survey shows that CVD is the main cause of death in T2DM patients, accounting for $65 \%$ of the mortality rate in T2DM patients[6]. Therefore, the treatment of T2DM is not only to control blood sugar, but also to reduce other risk factors of CVD, such as obesity, hypertension, hyperlipidemia, and blood hypercoagulability.

Many studies have confirmed that diabetic patients are often accompanied by excessive activation of platelets, which can easily lead to thrombosis and induce adverse cardiovascular events [7]. Therefore, anti-platelet aggregation therapy has become an indispensable part of preventing cardiovascular events in T2DM. In clinical work, the method of measuring platelet aggregation function is often used to reflect the platelet activation state [8]. This method is to expose platelets to different inducers (such as ADP, collagen, epinephrine, $A A$ ) in vitro, and use light transmission aggregation measurement (LTA) to monitor platelet aggregation ability. It is often used clinically to monitor the effect of antiplatelet therapy.

Both CD62p and PAC-1 are highly sensitive and specific markers that reflect the activation state of platelets. Among them, CD62p is a platelet activation-dependent granular membrane protein, also known as GMP-140, also known as P-Selectin, a member of the selectin family (one of the serum endothelial adhesion markers, which also includes vascular cell adhesion molecule-1 (VCAM-1), intracellular adhesion molecule-1 (ICAM-1)). PAC-1 is the GPIIb/Illa complex fibrinogen receptor. Several studies have confirmed that these two indicators can be used in the monitoring and early prevention of platelet activation in hypercoagulable diseases [9].

As a new type of hypoglycemic drugs, glucagon-like peptide-1 (GLP-1) receptor agonists have received more and more attention in recent years. In addition to lowering blood sugar, these drugs also showed good effects in reducing the cardiovascular risk of T2DM [10,11]. Exenatide is a commonly used clinical GLP-1 receptors (GLP-1R) agonist. A number of clinical trials that have been completed so far have found that [12-15] exenatide can not only effectively reduce the blood glucose level of patients with T2DM, but also has obvious effects other than hypoglycemic effects, such as losing weight, lowering blood pressure, regulating blood lipids, and improving endothelial dysfunction caused by hyperglycemia and hyperlipidemia. Studies have confirmed that GLP-1R are high expressed in mouse and human platelets [16]. Cameron-Vendrig et al. [17] confirmed that the GLP-1R agonist exenatide can not only inhibit the aggregation of human and mouse platelets in vitro, but also inhibit mice arterial thrombosis in vivo. At present, the research on the effect of GLP-1R agonists on platelet activation function is mostly limited to animal experiments and in vitro experiments [16-18], and clinical studies on the effect of platelet activation function in T2DM patients have not been reported.

To this end, we designed and conducted a small sample control study to explore the changes of platelet aggregation and its activation markers CD62p and PAC- 1 in peripheral blood of patients with T2DM after 
exenatide treatment, as well as the possible related factors. It aims to provide a theoretical basis for the clinical application of GLP-1R agonists and the prevention and treatment of diabetes-related cardiovascular diseases.

\section{Study Objects And Methods}

\section{Study object}

A total of 30 newly diagnosed T2DM patients (case group) admitted to the Department of Endocrinology of the First Affiliated Hospital of Anhui Medical University from October 2018 to November 2019 were selected, including 20 males and 10 females. Inclusion criteria: male or female aged 20-75 years; BMI 24 $\sim 40 \mathrm{~kg} / \mathrm{m} 2$; HbA1c 7.5 10\%; glutamate decarboxylase antibody was negative. Received lifestyle intervention for at least 1 month; never received never received hypoglycemic drugs (including oral never received hypoglycemic drugs, GLP-1R agonists, insulin, etc.); not taking lipid-regulating drugs and antihypertensive drugs; not taking antiplatelet and anticoagulant drugs; not taking any medication that affects weight. Exclusion criteria: intolerance to GLP-1R agonists; history of blood system and chronic infectious diseases; cardiovascular and cerebrovascular events in the past 6 months; pregnant patients or recent pregnancy planners; type 2 diabetes with acute metabolic disorders; obvious abnormal heart, liver and kidney function; a history of medullary thyroid cancer; a history of gastrointestinal, pancreatic disease, and gastrointestinal surgery; received weight loss treatment in the past 6 months; secondary to other endocrine diseases and symptomatic obesity caused by other reasons; those who cannot cooperate to complete clinical research.

In addition, 30 patients with normal glucose tolerance (control group) who received physical examination at the Health Management Center of the First Affiliated Hospital of Anhui Medical University during the same period were selected, including 21 males and 9 females. Inclusion criteria: males or females aged

20 to 75 years; BMI 24 to $40 \mathrm{~kg} / \mathrm{m}^{2}$; normal glucose tolerance (FPG $<6.1 \mathrm{mmol} / \mathrm{L}, \mathrm{HbA} 1 \mathrm{c}<5.7 \%$ ); not taking lipid-regulating drugs and antihypertensive drugs; not taking antiplatelet and anticoagulant drugs; not taking any medication that affects weight.

This study was approved by the Medical Ethics Committee of the First Affiliated Hospital of Anhui Medical University, and all subjects signed the informed consent form.

\section{Study methods}

Individuals included in the case group were supervised by professionals in the fields of diet, exercise, and blood sugar monitoring throughout the study. Also, they were commenced on exenatide treatment ( $5 \mu \mathrm{g}$, sc, bid). Four weeks later, the dose of exenatide was increased to $10 \mu \mathrm{g}$ (sc, bid), and the treatment continued for another four weeks, with a total of 8 weeks of exenatide treatment. One telephone follow-up was conducted every week while an outpatient follow-up was scheduled monthly. If nausea, vomiting, or other digestive symptoms occurred during the higher-dose exenatide treatment ( $10 \mu \mathrm{g}$, sc, bid), a reduced dose of exenatide ( $5 \mu \mathrm{g}, \mathrm{sc}$, bid) should be administered till the higher-dose treatment was resumed a 
week later. If the patient responded poorly to an increased dose of exenatide, he/she should continue the lower-dose treatment till the end of the study. Should serious hyperglycemia (FPG levels at two different time points both exceeding $13.9 \mathrm{mmol} / \mathrm{L}$ ) develop during the study, the patient was approved to withdraw from the study upon completion of relevant examinations.

Ulnar vein blood was drawn after fasting for at least 8 hours. Blood samples were collected, processed, and analyzed as required. A platelet aggregation system (Helena Laboratories, US) was used by a professional to determine the rates of platelet aggregation (to epinephrine (EPI), collagen, arachidonic acid (AA), and adenosine diphosphate (ADP)) pre- and post-exenatide treatment with light transmittance aggregometry (LTA). Three-color flow cytometry (FACSCalibur Flow Cytometer, BD, US) was performed for detection of platelet CD62p and PAC-1 (represented by the percentage of positive platelet for each activation marker) in whole-blood samples at the commencement and the end of exenatide treatment. an automatic biochemical analyzer (COBAS 8000, Roche, Switzerland) was utilized to measure the levels of fasting plasma glucose (FPG), total cholesterol (TCH), triglyceride (TG), low-density lipoprotein (LDL-C), and high-density lipoprotein (HDL-C) at Week 0 and at Week 8. An automatic coagulation analyzer (AYL-4013, Stago, France) was used for determination of prothrombin time (PT), international normalized ratio (INR), fibrinogen (FIB), activated partial thromboplastin time (APTT), fibrin degradation products (FDP), and d-dimer. An automatic hematology analyzer (XE-2100, Sysmex, Japan) was applied to the calculation of blood platelet counts (BPCs) at Week 0 and at Week 8. A Glycosylated hemoglobin analyzer (AYFY24319, BIO-RAD, Japan) was utilized to quantify glycosylated hemoglobin A1c (HbA1c) pre- and post-exenatide treatment. FPG was measured by the hexokinase method. TG and TCH were analyzed using enzymatic colorimetric methods. High-density lipoprotein cholesterol (HDL-C) was measured by direct methods. Low-density lipoprotein cholesterol (LDL-C) values were calculated using equations. Measurements of PT, FIB, and APTT were performed in the magnetic bead-based settings. Values of INR and PT activity were calculated directly. FDP and d-dimer were detected via immunoturbidimetry. PLT was analyzed using optical methods. $\mathrm{HbA1} \mathrm{c}$ values were obtained from high-pressure liquid chromatography (HPLC). Nitrogen monoxide (NO) test: $2.0 \mathrm{~mL}$ of venous blood was collected, centrifuged and stored at $-70^{\circ} \mathrm{C}$ for future use. After all blood samples were collected, the nitrate reductase assay (Nanjing Jiancheng Bioengineering Institute) was performed as instructed by the manufacturer. The concentration of serum NO was measured based on the optical density (OD) at $550 \mathrm{~nm}$. Each patient's body height (m), body weight $(\mathrm{kg})$, and waist were measured to calculate his/her body mass index (BMI) value according to the following equation: $\mathrm{BMI}=$ body weight $(\mathrm{kg}) /$ body height $(\mathrm{m})^{2}$. Differences $(\Delta)$ pre- and postexenatide treatment were calculated using the values of the above-mentioned clinical indicators measured at Week 0 and at Week 8.

\section{Statistical methods}

The SPSS 21.0 statistical software was used to process the data, and the measurement data conforming to the normal distribution were expressed as mean \pm standard deviation $(\overline{\mathrm{x}} \pm \mathrm{s})$. The comparison of variables between the case group and the control group by independent sample $t$ test and $\otimes 2$ test; the comparison of variables before and after treatment in the case group by paired $t$ test. Pearson correlation 
analysis explored the correlation between the changes in platelet aggregation function before and after exenatide treatment and the changes in other variables. Multiple linear regression analysis was used to explored the independent influencing factors of platelet aggregation function before and after exenatide treatment. Test level $\mathrm{a}=0.05$, two-sided $\mathrm{P}<0.05$ indicates that the difference is statistically significant.

\section{Result}

\section{Comparison of clinical data and biochemical indicators between case group and control group}

Compared with the control group, the levels of TG, FPG, HbA1c, FIB, CD62p and PAC-1 before treatment in the case group and the platelet aggregation rates induced by epinephrine, ADP and AA in case group were significantly higher than those in the control group $(P<0.05)$, the levels of HDL-C and NO were lower than those of the control group $(P<0.05)$, and there was no significant difference in other clinical indicators between the two groups $(P>0.05)$, Table 1,2 .

Table 1

Comparison of clinical data and biochemical indicators between case group and control group $(\%, \overline{\mathrm{x}} \pm \mathrm{s})$

\begin{tabular}{|c|c|c|c|c|}
\hline Variables & Control group $(n=30)$ & Case group $(n=30)$ & $x^{2} / /$ t values & $P$ values \\
\hline Sex(male/female) & $21 / 9$ & $20 / 10$ & 0.077 & 0.781 \\
\hline Age(years) & $40.23 \pm 10.83$ & $43.10 \pm 11.19$ & 1.008 & 0.317 \\
\hline weight (kg) & $83.94 \pm 11.68$ & $87.93 \pm 13.70$ & 1.215 & 0.229 \\
\hline BMI $\left(\mathrm{kg} / \mathrm{m}^{2}\right)$ & $29.16 \pm 3.12$ & $29.58 \pm 3.33$ & 0.497 & 0.621 \\
\hline Waist (cm) & $104.23 \pm 8.62$ & $105.37 \pm 9.77$ & 0.587 & 0.695 \\
\hline SBP $(m m H g)$ & $133.50 \pm 9.34$ & $136.60 \pm 9.26$ & 0.321 & 0.723 \\
\hline $\mathrm{DBP}(\mathrm{mmHg})$ & $86.84 \pm 10.55$ & $88.23 \pm 11.45$ & 0.387 & 0.701 \\
\hline $\mathrm{TCH}(\mathrm{mmol} / \mathrm{L})$ & $4.49 \pm 1.22$ & $4.64 \pm 1.06$ & 1.121 & 0.263 \\
\hline TG (mmol/L) & $1.83 \pm 1.47$ & $2.92 \pm 1.83$ & 3.217 & 0.012 \\
\hline LDL-C (mmol/L) & $2.37 \pm 0.75$ & $2.56 \pm 0.80$ & 1.687 & 0.195 \\
\hline $\mathrm{HDL}-\mathrm{C} \mathrm{mmol} / \mathrm{L})$ & $1.21 \pm 0.41$ & $0.99 \pm 0.30$ & 2.985 & 0.038 \\
\hline FPG $(\mathrm{mmol} / \mathrm{L})$ & $5.47 \pm 0.26$ & $11.67 \pm 4.06$ & 6.891 & $<0.001$ \\
\hline HbA1c (\%) & $5.51 \pm 0.19$ & $8.81 \pm 1.09$ & 5.885 & $<0.001$ \\
\hline $\mathrm{NO}(\mu \mathrm{mol} / \mathrm{L})$ & $79.4 \pm 11.2$ & $68.1 \pm 14.7$ & 3.012 & 0.015 \\
\hline
\end{tabular}


Table 2

Comparison of coagulation function and platelet aggregation function between case group and control group $(\overline{\mathrm{x}} \pm \mathrm{s})$

\begin{tabular}{|c|c|c|c|c|}
\hline Variables & Control group $(n=30)$ & Case group $(n=30)$ & $t$ values & $P$ values \\
\hline $\operatorname{PLT}\left(\times 10^{12} \mathrm{~g} / \mathrm{L}\right)$ & $203.86 \pm 56.44$ & $211.02 \pm 52.29$ & 0.331 & 0.698 \\
\hline PT (s) & $10.92 \pm 1.73$ & $11.86 \pm 1.58$ & 0.289 & 0.746 \\
\hline PTA (\%) & $104.22 \pm 13.68$ & $105.93 \pm 12.05$ & 0.293 & 0.701 \\
\hline INR & $1.36 \pm 1.74$ & $1.31 \pm 1.81$ & 0.305 & 0.738 \\
\hline APTT (s) & $41.22 \pm 44.83$ & $40.08 \pm 43.75$ & 0.321 & 0.712 \\
\hline $\mathrm{FIB}(\mathrm{g} / \mathrm{L})$ & $2.11 \pm 0.55$ & $3.38 \pm 0.78$ & 2.983 & 0.042 \\
\hline TT (s) & $15.22 \pm 1.51$ & $16.59 \pm 1.37$ & 0.387 & 0.665 \\
\hline $\mathrm{FDP}(\mu \mathrm{g} / \mathrm{mL})$ & $1.39 \pm 1.25$ & $1.78 \pm 1.51$ & 1.954 & 0.098 \\
\hline $\mathrm{DD}(\mu \mathrm{g} / \mathrm{mL})$ & $0.36 \pm 0.39$ & $0.37 \pm 0.45$ & 0.327 & 0.711 \\
\hline CD62p (\%) & $7.24 \pm 4.47$ & $15.16 \pm 8.23$ & 8.526 & $<0.001$ \\
\hline PAC-1 (\%) & $12.35 \pm 5.19$ & $28.71 \pm 11.62$ & 7.847 & $<0.001$ \\
\hline EPI induction (\%) & $82.15 \pm 5.37$ & $87.23 \pm 6.84$ & 3.238 & 0.002 \\
\hline COLL induction (\%) & $84.25 \pm 5.14$ & $87.62 \pm 8.15$ & 1.572 & 0.121 \\
\hline ADP induction (\%) & $82.38 \pm 6.24$ & $87.51 \pm 9.21$ & 2.290 & 0.026 \\
\hline AA induction (\%) & $83.41 \pm 6.17$ & $90.17 \pm 3.19$ & 5.632 & $<0.001$ \\
\hline
\end{tabular}

Comparison of clinical indicators after 0 weeks and 8 weeks of exenatide treatment in case group subjects

After 8 weeks of exenatide treatment, the levels of weight, BMI, waist, SBP, TCH, TG, LDL-C, FPG, HbA1c, FIB, CD62p and PAC-1, as well as platelet aggregation rates induced by epinephrine and AA were significantly decreased in case group compared with 0 weeks $(P<0.05)$, the levels of HDL-C and NO were significantly increased $(P<0.05)$, while DBP, PT, PTA, APTT, INR, TT, FDP, DD and platelet aggregation rates (collagen and ADP as inducers) had no significant differences before and after treatment $(P>0.05)$, Table 3, Table 4, Fig. 1. 
Table 3

Comparison of clinical data and biochemical indexes before and after exenatide treatment in case group $(\overline{\mathrm{x}} \pm \mathrm{s})$

\begin{tabular}{|c|c|c|c|c|}
\hline Variables & Exenatide-pre $(n=30)$ & Exenatide -post $(n=30)$ & $t$ values & $P$ values \\
\hline Weight (kg) & $87.93 \pm 13.70$ & $83.10 \pm 14.36$ & 4.626 & 0.002 \\
\hline BMI (kg/m2) & $29.58 \pm 3.33$ & $27.92 \pm 3.27$ & 3.524 & 0.016 \\
\hline Waist (cm) & $105.37 \pm 9.77$ & $99.22 \pm 9.4$ & 5.912 & $<0.001$ \\
\hline $\mathrm{SBP}(\mathrm{mmHg})$ & $136.60 \pm 9.26$ & $131.33 \pm 8.81$ & 2.256 & 0.028 \\
\hline $\mathrm{DBP}(\mathrm{mmHg})$ & $88.23 \pm 11.45$ & $87.71 \pm 10.92$ & 0.416 & 0.671 \\
\hline $\mathrm{TCH}(\mathrm{mmol} / \mathrm{L})$ & $4.64 \pm 1.06$ & $3.78 \pm 0.75$ & 3.271 & 0.031 \\
\hline $\mathrm{TG}(\mathrm{mmol} / \mathrm{L})$ & $2.92 \pm 1.83$ & $1.82 \pm 0.72$ & 4.317 & 0.009 \\
\hline LDL-C (mmol/L) & $2.56 \pm 0.80$ & $2.19 \pm 0.66$ & 2.925 & 0.048 \\
\hline HDL-C mmol/L) & $0.99 \pm 0.30$ & $1.08 \pm 0.21$ & 2.968 & 0.041 \\
\hline FPG (mmol/L) & $11.67 \pm 4.06$ & $6.90 \pm 1.20$ & 6.891 & $<0.001$ \\
\hline HbA1c (\%) & $8.81 \pm 1.09$ & $7.01 \pm 1.11$ & 5.885 & $<0.001$ \\
\hline $\mathrm{NO}(\mu \mathrm{mol} / \mathrm{L})$ & $68.1 \pm 14.7$ & $89.6 \pm 15.8$ & 6.336 & $<0.001$ \\
\hline \multicolumn{5}{|c|}{ 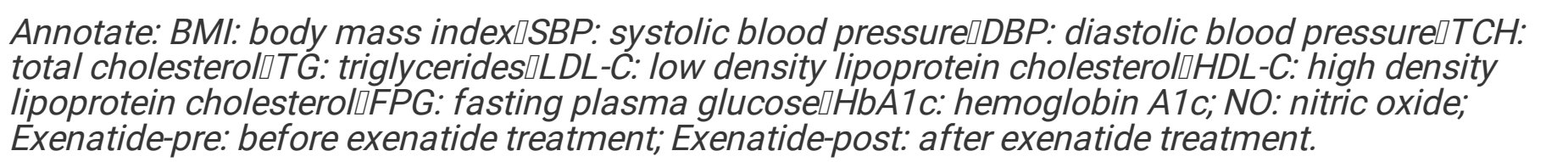 } \\
\hline
\end{tabular}


Table 4

Comparison of coagulation function and platelet aggregation function before and after exenatide treatment in case group $(\overline{\mathrm{x}} \pm \mathrm{s})$

\begin{tabular}{|c|c|c|c|c|}
\hline Variables & Exenatide-pre $(n=30)$ & Exenatide -post $(n=30)$ & $t$ values & $P$ values \\
\hline PLT $\left(\times 10^{12} \mathrm{~g} / \mathrm{L}\right)$ & $211.02 \pm 52.29$ & $218.03 \pm 53.82$ & 0.292 & 0.728 \\
\hline PT (s) & $11.86 \pm 1.58$ & $11.65 \pm 1.30$ & 0.325 & 0.581 \\
\hline PTA (\%) & $105.93 \pm 12.05$ & $107.05 \pm 12.95$ & 0.443 & 0.476 \\
\hline INR & $1.31 \pm 1.81$ & $1.29 \pm 1.84$ & 0.298 & 0.711 \\
\hline APTT (s) & $40.08 \pm 43.75$ & $32.90 \pm 4.33$ & 1.901 & 0.104 \\
\hline $\mathrm{FIB}(\mathrm{g} / \mathrm{L})$ & $3.38 \pm 0.78$ & $2.89 \pm 0.63$ & 2.951 & 0.044 \\
\hline TT (s) & $16.59 \pm 1.37$ & $17.14 \pm 3.06$ & 0.521 & 0.382 \\
\hline $\mathrm{FDP}(\mu \mathrm{g} / \mathrm{mL})$ & $1.78 \pm 1.51$ & $1.66 \pm 1.11$ & 1.037 & 0.165 \\
\hline $\mathrm{DD}(\mu \mathrm{g} / \mathrm{mL})$ & $0.37 \pm 0.45$ & $0.29 \pm 0.30$ & 0.783 & 0.321 \\
\hline CD62p (\%) & $15.16 \pm 8.23$ & $10.43 \pm 7.41$ & 3.937 & 0.019 \\
\hline PAC-1 (\%) & $28.71 \pm 11.62$ & $19.25 \pm 6.86$ & 4.152 & 0.015 \\
\hline EPI induction (\%) & $87.23 \pm 6.84$ & $81.62 \pm 9.02$ & 3.151 & 0.028 \\
\hline COLL induction (\%) & $87.62 \pm 8.15$ & $84.59 \pm 6.24$ & 1.932 & 0.092 \\
\hline ADP induction (\%) & $87.51 \pm 9.21$ & $85.37 \pm 6.47$ & 1.892 & 0.106 \\
\hline AA induction (\%) & $90.17 \pm 3.19$ & $84.62 \pm 7.12$ & 3.271 & 0.024 \\
\hline \multicolumn{5}{|c|}{ 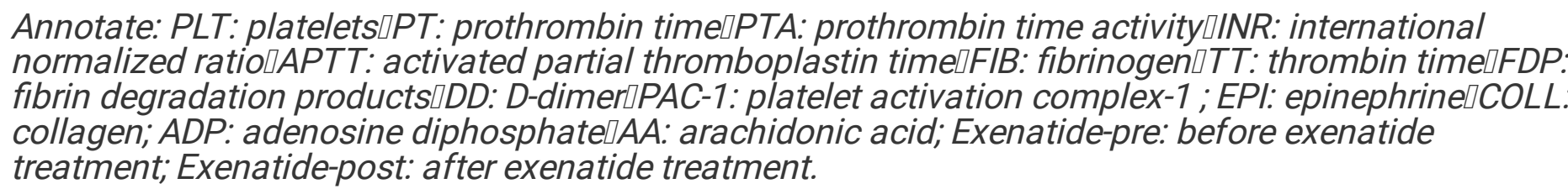 } \\
\hline
\end{tabular}

The correlation of the change values of platelet aggregation rates ( $\Delta$ platelet aggregation rates) with epinephrine and $A A$ as inducers and the change values of other clinical parameters ( $\Delta$ values) in the case group

Pearson correlation analysis showed that the $\Delta$ platelet aggregation rates $(\triangle \mathrm{EPI}, \triangle \mathrm{AA})$ before and after 8 weeks of exenatide treatment in the case group were positively correlated with $\Delta \mathrm{BMI}, \Delta$ weight, $\Delta$ waist, $\triangle \mathrm{TCH}, \Delta \mathrm{TG}, \triangle \mathrm{LDL}-\mathrm{C} \square \triangle \mathrm{FPG}, \triangle \mathrm{HbA} 1 \mathrm{c}, \triangle \mathrm{CD} 62 \mathrm{p}$ and $\triangle \mathrm{PAC}-1$, and negatively correlated with $\triangle \mathrm{HDL}-\mathrm{C}$ and $\Delta \mathrm{NO}(\mathrm{P}<0.05)$, and no significant correlation with $\Delta \mathrm{SBP}$ and $\Delta \mathrm{FIB}(\mathrm{P}>0.05)$, Fig. 3.

Factors affecting platelet aggregation before and after treatment with exenatide 
According to the results of Pearson correlation analysis, $\triangle \mathrm{BMI}, \Delta$ waist, $\Delta$ weight, $\Delta \mathrm{TCH}, \Delta \mathrm{TG}, \Delta \mathrm{LDL}-\mathrm{C}$, $\triangle \mathrm{HDL}-\mathrm{C}, \Delta \mathrm{FPG}, \triangle \mathrm{HbA} 1 \mathrm{c}, \Delta \mathrm{NO}, \triangle \mathrm{CD} 62 \mathrm{p}$, and $\triangle \mathrm{PAC}-1$ were included in the multiple linear regression analysis as independent variables, and $\triangle$ platelet aggregation rates $(\triangle \mathrm{EPI}, \triangle \mathrm{AA})$ as the dependent variable. The results show that $\triangle \mathrm{NO}, \triangle \mathrm{CD} 62 \mathrm{p}$ and $\triangle \mathrm{PAC}-1$ are independent risk factors affecting $\Delta$ platelet aggregation rates $(\triangle \mathrm{EPI} \triangle \triangle \mathrm{AA})(P<0.05)$, Table 5 . 
Table 5

Multiple linear regression analysis of $\Delta$ platelet aggregation rates and $\Delta$ value of other clinical and biochemical indicators

\begin{tabular}{|c|c|c|c|c|c|c|c|c|}
\hline \multirow[t]{2}{*}{ Variables } & \multicolumn{4}{|l|}{$\Delta \mathrm{EPI}$} & \multicolumn{4}{|l|}{$\triangle \mathrm{AA}$} \\
\hline & $\beta$ & $\begin{array}{l}t \\
\text { values }\end{array}$ & $\begin{array}{l}P \\
\text { values }\end{array}$ & $95 \% \mathrm{Cl}$ & $\beta$ & $\begin{array}{l}t \\
\text { values }\end{array}$ & $\begin{array}{l}P \\
\text { values }\end{array}$ & $95 \% \mathrm{Cl}$ \\
\hline$\Delta$ Weight & 0.227 & 1.239 & 0.226 & $\begin{array}{l}-0.004- \\
0.106\end{array}$ & 0.007 & 0.151 & 0.881 & $\begin{array}{l}-0.086- \\
0.100\end{array}$ \\
\hline$\Delta$ Waist & 0.000 & -0.046 & 0.964 & $\begin{array}{l}0.009- \\
0.009\end{array}$ & 0.004 & -0.059 & 0.953 & $\begin{array}{l}-0.010- \\
0.009\end{array}$ \\
\hline$\triangle \mathrm{BMI}$ & 0.111 & 1.004 & 0.325 & $\begin{array}{l}-0.117- \\
0.005\end{array}$ & 0.092 & 0.843 & 0.413 & $\begin{array}{l}-0.136- \\
0.319\end{array}$ \\
\hline$\triangle \mathrm{TCH}$ & 0.020 & 1.320 & 0.199 & $\begin{array}{l}-0.011- \\
0.051\end{array}$ & -0.001 & -0.073 & 0.943 & $\begin{array}{l}-0.039- \\
0.036\end{array}$ \\
\hline$\Delta \mathrm{TG}$ & 0.011 & 0.991 & 0.332 & $\begin{array}{l}-0.012- \\
0.035\end{array}$ & 0.000 & 0.099 & 0.993 & $\begin{array}{l}-0.026- \\
0.026\end{array}$ \\
\hline$\Delta \mathrm{LDL}-\mathrm{C}$ & 0.013 & 0.801 & 0.421 & $\begin{array}{l}-0.021- \\
0.047\end{array}$ & 0.019 & 0.706 & 0.386 & $\begin{array}{l}-0.060- \\
0.120\end{array}$ \\
\hline$\Delta \mathrm{HDL}-\mathrm{C}$ & -0.029 & -0.703 & 0.489 & $\begin{array}{l}-0.113- \\
0.055\end{array}$ & -0.004 & -1.046 & 0.306 & $\begin{array}{l}-0.012- \\
0.004\end{array}$ \\
\hline$\triangle \mathrm{FPG}$ & -0.196 & -1.066 & 0.296 & $\begin{array}{l}-0.010- \\
0.003\end{array}$ & -0.189 & -1.030 & 0.302 & $\begin{array}{l}-0.013- \\
0.005\end{array}$ \\
\hline$\Delta \mathrm{HbA} 1 \mathrm{c}$ & 0.091 & 0.830 & 0.415 & $\begin{array}{l}-0.136- \\
0.318\end{array}$ & 0.085 & 0.783 & 0.321 & $\begin{array}{l}-0.225- \\
0.409\end{array}$ \\
\hline$\Delta \mathrm{NO}$ & -0.194 & -2.981 & 0.032 & $\begin{array}{l}0.041- \\
0.943\end{array}$ & -0.252 & -4.285 & 0.000 & $\begin{array}{l}0.065- \\
0.132\end{array}$ \\
\hline$\Delta \mathrm{CD} 62 \mathrm{p}$ & 0.276 & 4.274 & 0.000 & $\begin{array}{l}1.058- \\
1.803\end{array}$ & 0.269 & 3.868 & 0.008 & $\begin{array}{l}1.038- \\
1.531\end{array}$ \\
\hline$\triangle \mathrm{PAC}-1$ & 0.209 & 2.975 & 0.012 & $\begin{array}{l}1.035- \\
2.002\end{array}$ & 0.483 & 8.572 & 0.000 & $\begin{array}{l}1.028- \\
1.084\end{array}$ \\
\hline \multicolumn{9}{|c|}{ 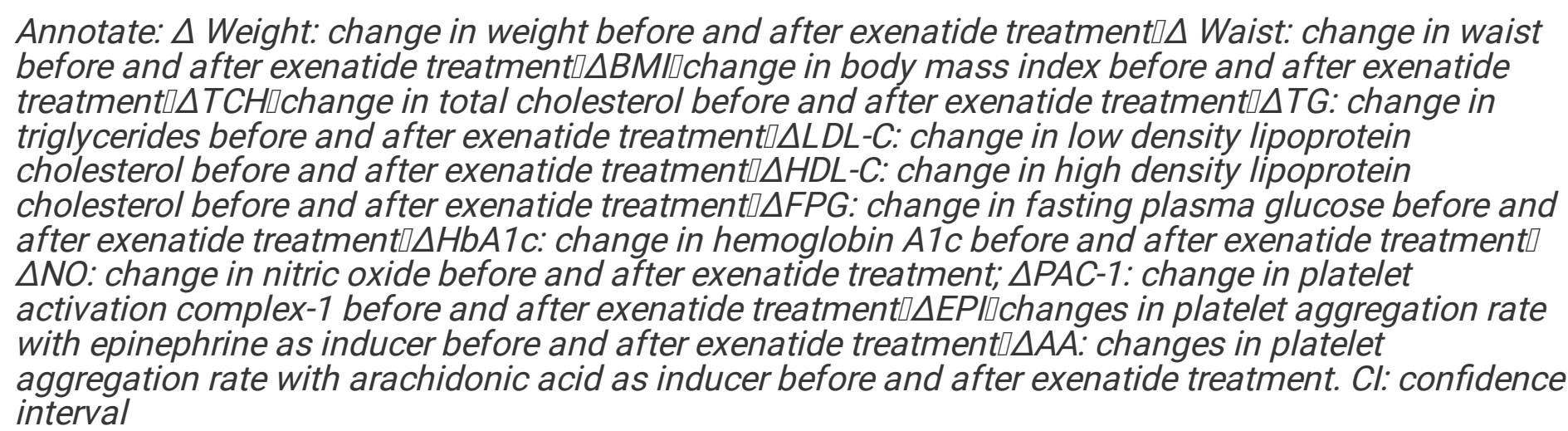 } \\
\hline
\end{tabular}




\section{Discussion}

Despite the fact that all subjects in this study were included in the category of overweight or obesity, in the case group, the accumulation of cardiovascular risk factors in T2DM patients is more obvious, including a significant increase in the blood sugar, blood pressure, blood fat, and FIB levels, which indicated that compared with those with normal glucose tolerance in the control group, the T2DM patients appeared to be at higher risk of developing CVD. Apart from this, the levels of FIB and platelet activation markers, and the rates of platelet aggregation in the case group were significantly higher than in the control group, indicating a relatively high degree of functional activation of platelets, a dramatic enhancement of aggregation function, and a prothrombotic state in the T2DM patients.

The molecular mechanism of increased platelet aggregation and adhesion in T2DM patients is not yet fully understood. Existing studies have found that: 1) insulin resistance becomes less effective in inhibiting hyperfunction of platelets [19]; 2) in a high-glucose environment, the number of glycosylated products increases due to non-enzymatic glycosylation of the platelet membrane, which consequently reduces the membrane fluidity, promotes platelet aggregation and adhesion and improves the sensitivity of platelets to pro-aggregation substances $[20,21] ; 3)$ an increase of P2Y12 on platelet in patients with diabetes mellitus (DM) can induce protein kinase $A$ (PKA)-mediated vasodilation, leading to reduced cyclic adenosine monophosphate (CAMP)-dependent phosphorylation of vasodilator-stimulated phosphoproteins (VASP-PS) and lower bioavailability of NO in endothelial cells [20, 22]. Additionally, hypertriglyceridemia and very-low-density lipoprotein (VLDL) can trigger platelet hyperfunction in DM patients through interaction between apolipoprotein E (apoE) and platelet LDL receptor [21]. A study [23] revealed that in T2DM, the increase in the level of FIB in the peripheral blood of patients with T2DM may be caused by the combined effect of inflammatory cytokines and insulin on the liver, resulting in increased liver synthesis.

As is well known, the potential cardiovascular protective activity of GLP-1R agonists is attributed to the anti-hypoglycemic effects of these agents, which help improve insulin resistance, aid weight loss, lower blood pressure, modify lipid distribution and directly act on the myocardium and blood vessel endothelium. The study by Martinez et al. [24] showed an average weight loss of $3.9 \mathrm{~kg}$ after six months of exenatide treatment. In a 30-week randomized, double-blind, controlled clinical trial, it was found that exenatide could significantly reduce SBP in patients with newly diagnosed T2DM, while DBP was also slightly reduced [25]. Sun et al. [26] carried out a meta-analysis of 13 studies (GLP-1R agonist treatment requires at least a 6-week duration) and pointed out that GLP-1R agonists could moderately reduce the LDL-C, TCH, and TG levels. In this study, it was found that following the 8-week exenatide treatment, the T2DM patients lost $4.8 \mathrm{~kg}$, the SBP level was reduced by $5.5 \mathrm{mmHg}$, and the DBP level was slightly decreased,however, the differences pre- and post-treatment were not statistically significant. Likewise, blood lipids were also improved after 8 weeks of exenatide treatment, manifested by reduced TCH, TG, and LDL-C levels and an increase in HDL-C, which was basically consistent with the aforementioned findings. Presently, it is widely accepted that GLP-1R agonist-mediated SBP reduction is probably 
associated with weight loss, improved endothelial function, natriuresis, and relaxation of renal vascular smooth muscles [27-29].

In fact, in addition to the above-mentioned beneficial effects of reducing the risk for CVD, it has become a popular interest of research to investigate the effects of GLP-1R agonists on the platelet aggregation/activation function $[17,18]$. Hemostatic time, clotting time, platelet activating markers, and the rate of platelet aggregation serve common indicators for the evaluation of platelet function [30-32]. The rate of platelet aggregation is considered as an important indicator for the platelet aggregation function, which plays an important role in the prevention, treatment, and monitoring of thrombosis. A range of specific markers have been released in the process of platelet activation, especially CD62p and PAC-1 [33]. CD62p is a transmembrane protein stored in a granules of platelets and Weibel-Palade bodies of endothelial cells. Under normal circumstances, CD62p only has a relatively low level of endothelial surface expression. In response to stimulation, the surface expression of platelets increases sharply to mediate the adhesion function of activated endothelial cells, mononuclear cells, and neutrophils using the lectin-like, $\mathrm{N}$-terminal domain. These activated cells not only promote fibrin deposition but also play a role in inflammatory response and thrombosis. Activated platelets treated with anti-CD62p antibodies no longer have adhesive attraction to each other, which shows that as one of the important markers of platelet activation, CD62p is able to mediate the adhesion between activated platelets or between endothelial cells and leukocytes [23]. PAC-1, as a platelet membrane glycoprotein $\mathrm{Ilb} / \mathrm{Illa}$ complex and abundant platelet surface glycoprotein, consists of binding sites specific to attachment proteins such as fibrinogen, fibronectin, and von Willebrand factor (vWF). Under normal conditions, PAC-1 exists as a monomer without ligand-binding ability. Upon activation of platelets, the PAC-1 receptor reveals its ligand-binding mechanism and binds to specific attachment proteins, which promotes platelet-fibrinogen-platelet aggregation and eventually contributes to platelet thrombus formation. Apart from this, PAC-1 also plays a role in intracellular signal transduction and thus it is useful for direct detection of activated platelets [34]

In terms of coagulation function, this study found that the anticoagulant indexes PT, APTT, INR, TT, PTA, FDP, and DD did not significantly change after 8 weeks of exenatide treatment, and the FIB in T2DM patients after 8 weeks of exenatide treatment was significantly decreased compared with that before treatment. As far as we know, this finding is the first to be reported. It is known that FIB is a protein with coagulation function synthesized in the liver, and is the coagulation factor with the highest content in plasma. As a marker of thrombosis and inflammation, FIB is an important reaction substrate for thrombosis, participates in the key steps of thrombosis, and plays a very important role in the pathogenesis of cardiovascular diseases. In this study, it was found that after 8 weeks of exenatide treatment, plasma FIB levels in T2DM patients were significantly reduced, but the relevant mechanism is still unclear, which may be related to exenatide inhibiting inflammation and improving insulin resistance [23].

In terms of platelet activation status, this study found that after 8 weeks of exenatide treatment in T2DM patients (newly diagnosed overweight or obese), platelet activation markers represented by CD62P and 
PAC-1, and platelet aggregation rates induced by epinephrine and AA were significantly reduced. Pearson and multiple linear regression correlation analysis showed that after exenatide treatment, the $\triangle$ platelet aggregation rates $(\triangle \mathrm{EPI}, \triangle \mathrm{AA})$ were significantly positively correlated with $\triangle \mathrm{CD} 62 \mathrm{p}$ and $\triangle \mathrm{PAC}-1$, and $\triangle C D 62 p$ and $\triangle P A C-1$ were independent factors affecting $\triangle$ platelet aggregation rates, indicating that Exenatide can significantly inhibit the activation of platelets in patients with T2DM, thereby decreasing the ability of peripheral blood platelets to aggregate. It is worth mentioning that in our study, no significant changes in the platelet aggregation rate with ADP and collagen as inducers were observed after 8 weeks of exenatide treatment. This suggested that there may be differences in the detection results of platelet aggregation function with different inducers in T2DM patients, and the application of single inducer may lead to bias in the study results, while the detection combined with multiple inducers can better guide clinical practice. Some studies have found that when the antiplatelet aggregation function is detected by turbidimetric method, the decrease of platelet aggregation rate is not obvious at the early stage, but it will decrease significantly over time [35]. We speculated that the platelet aggregation rate with ADP and collagen as inducers in this study might significantly decrease with the further extension of exenatide treatment, which requires further research to confirm.

In order to further understand the other influencing factors of $\Delta$ platelet aggregation rate after treatment with GLP-1R agonist exenatide, we also explored the correlation between $\Delta$ platelet aggregation rates and cardiovascular risk factors in T2DM patients, and the results showed that $\Delta$ platelet aggregation rates $(\Delta \mathrm{EPl}, \triangle \mathrm{AA})$ are positively correlated with $\Delta \mathrm{BMl}, \Delta$ waist, weight, $\Delta \mathrm{TCH} \square \Delta \mathrm{TG} \square \Delta \mathrm{LDL}-\mathrm{C} \square \Delta \mathrm{FPG}$ and $\mathrm{HbA} 1 \mathrm{c}$, negatively correlated with $\triangle \mathrm{HDL}-\mathrm{C}$ and $\triangle \mathrm{NO}$, and have no correlation with $\triangle \mathrm{SBP}$ and $\triangle \mathrm{FIB}$. Among them, $\Delta N O$ is an independent risk factor that affects the platelet aggregation rates, suggesting that the effect of exenatide on improving platelet function may be related to weight loss, lipid regulation, blood sugar reduction, and increase of NO concentration. Simeone et al. [36] randomly assigned 62 patients (obese subjects with prediabetes or early T2DM) to the liraglutide group and the lifestyle intervention group according to $1: 1$, and the two groups were monitored until the weight loss goal (-7\% of initial body weight) was achieved. The results showed that U-11-dehydro-TXB2 (a metabolite of thromboxane that reflects platelet activation) was significantly reduced after achievement of the weight loss target regardless of the intervention arm, suggesting that the inhibition of platelet activation by GLP-1R agonists is related to weight loss. Dyslipidemia is closely related to platelet activation [37]. Studies have shown that dyslipidemia, especially hypertriglyceridemia, is directly related to platelet function [38]. Ebara et al. [7] believe that oxidized HDL is negatively related to blood coagulation and fibrinolysis in patients with T2DM. In addition, many studies have confirmed that hyperglycemia can have a significant adverse effect on platelet function $[20,21]$. In addition to decreasing the fluidity of the platelet membrane and promoting platelet aggregation, coagulation factors and PAl-1 (plasminogen activator inhibitor-1) will also increase under the condition of hyperglycemia, breaking the balance of coagulation and fibrinolysis, and promoting thrombosis [39]. Besides improvements in blood sugar control and weight loss, the inhibitory effect of GLP-1R agonists on platelets has been verified in animal models $[17,18]$ and healthy volunteers [40]. Therefore, GLP-1R agonists have the potential, at least in theory, to regulate platelet 
activation directly through the effect on platelet function and indirectly through the control of body weight and metabolism. The above arguments further support the results of this study.

NO is considered to be the most important vasodilator factor secreted by vascular endothelial cells, which can relax vascular smooth muscle and dilate blood vessels. Liraglutide has been reported to inhibit platelet activation in animal models [17] and healthy volunteers [40] by increasing the concentration of NO. In vitro studies we have also confirmed that liraglutide can increase the expression of endothelial nitric oxide synthase (eNOS), and reduce the expression of inducible nitric oxide synthase (iNOS) at the levels of transcription and translation by inhibiting nuclear factor kappa B (NF-p65) phosphorylation to improve endothelial cell function, and prevent diabetic atherosclerosis [41]. Similarly, Jia and colleagues also confirmed that GLP-1R agonists regulate platelet activity by inducing eNOS-dependent mechanisms, increase the bioavailability of NO in vascular endothelial cells, and improve vascular function [18]. The above study results all suggest that GLP-1R agonists reduce platelet activation and inhibit thrombosis by enhancing the production and utilization of NO, which is basically consistent with the results of this study.

In fact, the molecular mechanism of the effect of GLP-1R agonists on platelet aggregation/activation function has not yet been elucidated. It is currently recognized that the adhesion/aggregation process of platelets is regulated by the balance between procoagulant and anti-aggregation circulatory agents (such as NO). NO stimulates soluble guanylate cyclase (sGC) in platelets, activates cyclic guanosine monophosphate (cGMP) and protein kinase $\mathrm{G}$ (PKG), and then inhibits platelet activation through various pathways. In addition, cGMP can indirectly increase cellular cAMP levels by inhibiting 3'phosphodiesterase to activate PKA [42] and induce eNOS activity [43]. The synergistic effect of cGMP and cAMP inhibit platelet aggregation $[44,45]$. Secondly, cGMP can also inhibit the activation of phosphoinositide3-kinase (PI3K) [46], causing the activation of the GP IIb-IIla fibrinogen receptor [47]. In addition to the CGMP-dependent pathway described above, there is evidence that NO can also regulate platelet function independently of cGMP without being affected by sGC [48-50]. Therefore, any change in eNOS activity or/and NO bioavailability by GLP-1R agonists is a key factor in determining platelet function $[18,51]$.

\section{Conclusion}

In short, this study found that the GLP-1R agonist exenatide can significantly reduce the platelet activation state and inhibit the platelet aggregation rate in T2DM patients. This effect may be related to weight loss, blood sugar reduction, lipid regulation, and increase of NO levels, and the levels of $\triangle N O$, $\triangle \mathrm{CD} 62 \mathrm{p}$, and $\triangle \mathrm{PAC}-1$ are independent factors that affect the $\Delta$ platelet aggregation rates. Of course, there are many shortcomings in this study, such as a single-center small sample study, lack of placebo control, short observation time, and subjects are all overweight/obese patients with T2DM. Whether the results can be extended to non-obese patients with T2DM still needs further study.

\section{Abbreviations}


ADP: adenosine diphosphate

AA: arachidonic acid

APTT: activated partial thromboplastin time

BMI: body mass index

COLL: collagen

cAMP: cyclic adenosine monophosphate

cGMP: cyclic guanosine monophosphate

DD: D-dimer

DBP: diastolic blood pressure

EPI: epinephrine

FPG: fasting plasma glucose

FIB: fibrinogen

FDP: fibrin degradation products

GLP-1R: glucagon-like peptide-1 receptor

HDL-C: high density lipoprotein cholesterol

HbA1c: hemoglobin A1c

INR: international normalized ratio

LDL-C: low density lipoprotein cholesterol

NO: nitric oxide

PLT: platelets

PT: prothrombin time

PTA: prothrombin time activity

PAC-1: platelet activation complex-1

PKG: protein kinase $\mathrm{G}$ 
PI3K: phosphoinositide3-kinase

SBP: systolic blood pressure

sGC: soluble guanylate cyclase

TCH: total cholesterol

TG: triglycerides

TT: thrombin time

T2DM: Type 2 diabetes mellitus

\section{Declarations}

\section{Ethics approval and consent to participate}

This study was approved by the Medical Ethics Committee of the First Affiliated Hospital of Anhui Medical University.

\section{Informed consent}

Informed consent was obtained from all individual participants included in the study.

\section{Data Availability}

The data sets used to support the findings of this study are available from the corresponding author upon request.

\section{Declarations of interest}

The authors declare no conflict of interest.

\section{Authors' contributions}

Yaqin Zhang and Ruofei Chen conceived and designed the study, analyzed the data, and wrote the paper; Yangyang Jia collected data with Yaqin Zhang; Mingwei Chen and Zongwen Shuai discussed results and advised during the completion of the study.

All authors read and approved the final manuscript.

\section{Acknowledgements}

The authors thank laboratory of Anhui Medical University and the participants of this study including statistician, doctors, nurses, and researchers from the First Affiliated Hospital of Anhui Medical University. 


\section{Funding}

This work was supported by the Natural Foundation of Anhui Province [N0.1808085MH279].

\section{References}

1. Beckman JA, Creager MA, Libby P. Diabetes and atherosclerosis: epidemiology, pathophysiology, and management. Jama. 2002; 287:19.

2. Chilton R, Wyatt J, Nandish S, Oliveros R, Lujan M. Cardiovascular comorbidities of type 2 diabetes mellitus: defining the potential of glucagonlike peptide-1-based therapies. Am J Med. 2011;124:1.

3. Vaidyula VR, Rao AK, Mozzoli M, Homko C, Cheung P, Boden G. Effects of hyperglycemia and hyperinsulinemia on circulating tissue factor procoagulant activity and platelet CD 40 ligand. Diabetes. 2006; 55:1.

4. Mylotte D, Kavanagh GF, Peace AJ, Tedesco AF, Carmody D, O'Reilly M, et al. Platelet reactivity in type 2 diabetes mellitus: a comparative analysis with survivors of myocardial infarction and the role of glycaemic control. Platelets. 2012; 23:6.

5. Angiolillo DJ, Bernardo E, Sabaté M, Jimenez-Quevedo P, Costa MA, Palazuelos J, et al. Impact of platelet reactivity on cardiovascular outcomes in patients with type 2 diabetes mellitus and coronary artery disease. J Am Coll Cardiol. 2007; 50:16.

6. Strain WD, Paldánius PM. Diabetes, cardiovascular disease and the microcirculation. Cardiovasc Diabetol. 2018; 17:1.

7. Ebara S, Marumo M, Mukai J, Ohki M, Uchida K, Wakabayashi I. Relationships of oxidized HDL with blood coagulation and fibrinolysis in patients with type 2 diabetes mellitus. J Thromb Thrombolysis. 2018; 45:2.

8. Osende JI, Fuster V, Lev El, Shimbo D, Rauch U, Marmur JD, et al. Testing platelet activation with a shear-dependent platelet function test versus aggregation-based tests: relevance for monitoring longterm glycoprotein Ilb/Illa inhibition. Circulation. 2001; 103:11.

9. Zhou AM, Xiang YJ, Liu EQ, Cai CH, Wu YH, Yang LB, Zeng CL: Salvianolic acid a inhibits platelet activation and aggregation in patients with type 2 diabetes mellitus. BMC Cardiovasc Disord. 2020; 20:1.

10. Marso SP, Daniels GH, Brown-Frandsen K, Kristensen P, Mann JF, Nauck MA, et al. Liraglutide and Cardiovascular Outcomes in Type 2 Diabetes. N Engl J Med. 2016; 375:4.

11. Marso SP, Bain SC, Consoli A, Eliaschewitz FG, Jódar E, Leiter LA, et al. Semaglutide and Cardiovascular Outcomes in Patients with Type 2 Diabetes. N Engl J Med. 2016; 375:19.

12. Lee YS, Jun HS: Anti-Inflammatory Effects of GLP-1-Based Therapies beyond Glucose Control. Mediators Inflamm. 2016; 2016:3094642.

13. Chaudhuri A, Ghanim H, Vora M, Sia CL, Korzeniewski K, Dhindsa S, et al. Exenatide exerts a potent antiinflammatory effect. J Clin Endocrinol Metab. 2012; 97:1. 
14. De Ciuceis C, Agabiti-Rosei C, Rossini C, Caletti S, Coschignano MA, Ferrari-Toninelli G, et al. Microvascular Density and Circulating Endothelial Progenitor Cells Before and After Treatment with Incretin Mimetics in Diabetic Patients. High Blood Press Cardiovasc Prev. 2018; 25:4.

15. Fadini GP, Miorin M, Facco M, Bonamico S, Baesso I, Grego F, et al. Circulating endothelial progenitor cells are reduced in peripheral vascular complications of type 2 diabetes mellitus. J Am Coll Cardiol. 2005; 45:9.

16. Steven S, Jurk K, Kopp M, Kröller-Schön S, Mikhed Y, Schwierczek K, et al. Glucagon-like peptide-1 receptor signalling reduces microvascular thrombosis, nitro-oxidative stress and platelet activation in endotoxaemic mice. Br J Pharmacol. 2017; 174:12.

17. Cameron-Vendrig A, Reheman A, Siraj MA, Xu XR, Wang Y, Lei X, et al. Glucagon-Like Peptide 1 Receptor Activation Attenuates Platelet Aggregation and Thrombosis. Diabetes 2016; 65:6.

18. Jia G, Aroor AR, Sowers JR. Glucagon-Like Peptide 1 Receptor Activation and Platelet Function. Beyond Glycemic Control. Diabetes. 2016; 65:6.

19. Vinik Al, Erbas T, Park TS, Nolan R, Pittenger GL. Platelet dysfunction in type 2 diabetes. 2001; 4:8.

20. Carrizzo A, Izzo C, Oliveti M, Alfano A, Virtuoso N, Capunzo M, et al. The Main Determinants of Diabetes Mellitus Vascular Complications: Endothelial Dysfunction and Platelet Hyperaggregation. Int J Mol Sci. 2018; 19:10.

21. Rollini F, Franchi F, Muñiz-Lozano A, Angiolillo DJ. Platelet function profiles in patients with diabetes mellitus. J Cardiovasc Transl Res. 2013; 6:3

22. Suslova TE, Sitozhevskii AV, Ogurkova ON, Kravchenko ES, Kologrivova IV, Anfinogenova Y, et al. Platelet hemostasis in patients with metabolic syndrome and type 2 diabetes mellitus: cGMP-and NO-dependent mechanisms in the insulin-mediated platelet aggregation. Front Physiol. 2014; 5:501.

23. Pretorius L, Thomson GJA, Adams RCM, Nell TA, Laubscher WA, Pretorius E. Platelet activity and hypercoagulation in type 2 diabetes. Cardiovasc Diabetol. 2018; 17:1.

24. Gorgojo-Martínez JJ, Gargallo-Fernández MA, Brito-Sanfiel M, Lisbona-Catalán A. Real-world clinical outcomes and predictors of glycaemic and weight response to exenatide once weekly in patients with type 2 diabetes: The CIBELES project. Int J Clin Pract. 2018; 72:3.

25. Drucker DJ, Buse JB, Taylor K, Kendall DM, Trautmann M, Zhuang D, et al. Exenatide once weekly versus twice daily for the treatment of type 2 diabetes: a randomised, open-label, non-inferiority study. Lancet (London, England). 2008; 372:9645.

26. Sun F, Wu S, Wang J, Guo S, Chai S, Yang Z, et al. Effect of glucagon-like peptide-1 receptor agonists on lipid profiles among type 2 diabetes: a systematic review and network meta-analysis. Clin Ther. 2015; 37:1.

27. Drucker DJ. The Cardiovascular Biology of Glucagon-like Peptide-1. Cell Metab. 2016; 24:1.

28. Sivertsen J, Rosenmeier J, Holst JJ, Vilsbøll T. The effect of glucagon-like peptide 1 on cardiovascular risk. Nat Rev Cardiol. 2012; 9:4. 
29. Lovshin JA, Barnie A, DeAlmeida A, Logan A, Zinman B, Drucker DJ. Liraglutide promotes natriuresis but does not increase circulating levels of atrial natriuretic peptide in hypertensive subjects with type 2 diabetes. Diabetes care. 2015; 38:1.

30. Gresele P. Diagnosis of inherited platelet function disorders: guidance from the SSC of the ISTH. J Thromb Haemost. 2015; 13:2.

31. Huskens D, Sang Y, Konings J, van der Vorm L, de Laat B, Kelchtermans H, et al. Standardization and reference ranges for whole blood platelet function measurements using a flow cytometric platelet activation test. PloS one. 2018; 13:2.

32. Asare R, Opoku-Okrah C, Danquah KO, Opare-Sem O, Addai-Mensah O, Gyamfi D, et al: Assessment of platelet indices and platelet activation markers in children with Plasmodium falciparum malaria. Malar J. 2020; 19:1.

33. Hou M, Yu J, Zhang L, Liu C. [Changes and significance of P-selectin and PAC-1 in coronary heart disease before and after stenting]. Zhonghua yi xue za zhi. 2014; 94:10.

34. Caron A, Théorêt JF, Mousa SA, Merhi Y. Anti-platelet effects of GPIIb/Illa and P-selectin antagonism, platelet activation, and binding to neutrophils. J Cardiovasc Pharmacol. 2002; 40:2.

35. Satoh K, Ozaki Y. [Attempts for aspirin monitoring with a new assay system, Ultegra Rapid Platelet Function Assay (RPFA), based on turbidimetric platelet agglutination of whole blood samples]. Rinsho Byori. 2006; 54:6.

36. Simeone P, Liani R, Tripaldi R, Di Castelnuovo A, Guagnano MT, Tartaro A, et al. ThromboxaneDependent Platelet Activation in Obese Subjects with Prediabetes or Early Type 2 Diabetes: Effects of Liraglutide- or Lifestyle Changes-Induced Weight Loss. Nutrients. 2018;10:12.

37. Paes AMA, Gaspar RS, Fuentes E, Wehinger S, Palomo I, Trostchansky A. Lipid Metabolism and Signaling in Platelet Function. Adv Exp Med Biol. 2019; 1127:97.

38. Boulet MM, Cheillan D, Di Filippo M, Buisson C, Michalski MC, Moulin P, et al. Large triglyceride-rich lipoproteins from fasting patients with type 2 diabetes activate platelets. Diabetes Metab. 2020; 46:1.

39. Kaur R, Kaur M, Singh J. Endothelial dysfunction and platelet hyperactivity in type 2 diabetes mellitus: molecular insights and therapeutic strategies. Cardiovasc Diabetol. 2018; 17:1.

40. Barale C, Buracco S, Cavalot F, Frascaroli C, Guerrasio A, Russo I. Glucagon-like peptide 1-related peptides increase nitric oxide effects to reduce platelet activation. Thromb Haemost. 2017; 117:6.

41. Dai Y, Mehta JL, Chen M. Glucagon-like peptide-1 receptor agonist liraglutide inhibits endothelin-1 in endothelial cell by repressing nuclear factor-kappa B activation. Cardiovasc Drugs Ther. 2013; 27:5.

42. Maurice DH, Haslam RJ. Molecular basis of the synergistic inhibition of platelet function by nitrovasodilators and activators of adenylate cyclase: inhibition of cyclic AMP breakdown by cyclic GMP. Mol Pharmacol. 1990; 37:5.

43. Santilli F, Simeone P, Liani R, Davì G. Platelets and diabetes mellitus. Prostaglandins Other Lipid Mediat. 2015; 120:28. 
44. Bowen R, Haslam RJ. Effects of nitrovasodilators on platelet cyclic nucleotide levels in rabbit blood; role for cyclic AMP in synergistic inhibition of platelet function by SIN-1 and prostaglandin E1. J Cardiovasc Pharmacol. 1991; 17:3.

45. Radomski MW, Palmer RM, Moncada S. The anti-aggregating properties of vascular endothelium: interactions between prostacyclin and nitric oxide. Br J Pharmacol. 1987; 92:3.

46. Pigazzi A, Heydrick S, Folli F, Benoit S, Michelson A, Loscalzo J. Nitric oxide inhibits thrombin receptor-activating peptide-induced phosphoinositide 3-kinase activity in human platelets. J Biol Chem. 1999; 274:20.

47. Zhang J, Zhang J, Shattil SJ, Cunningham MC, Rittenhouse SE. Phosphoinositide 3-kinase gamma and p85/phosphoinositide 3-kinase in platelets. Relative activation by thrombin receptor or betaphorbol myristate acetate and roles in promoting the ligand-binding function of alphallbbeta3 integrin. J Biol Chem. 1996; 271:11.

48. Tsikas D, Ikic M, Tewes KS, Raida M, Frölich JC. Inhibition of platelet aggregation by S-nitrosocysteine via cGMP-independent mechanisms: evidence of inhibition of thromboxane A2 synthesis in human blood platelets. FEBS letters. 1999; 442:2-3.

49. Sogo N, Magid KS, Shaw CA, Webb DJ, Megson IL. Inhibition of human platelet aggregation by nitric oxide donor drugs: relative contribution of cGMP-independent mechanisms. Biochem Biophys Res Commun. 2000; 279:2.

50. Beghetti M, Sparling C, Cox PN, Stephens D, Adatia I. Inhaled NO inhibits platelet aggregation and elevates plasma but not intraplatelet cGMP in healthy human volunteers. Am J Physiol Heart Circ Physiol. 2003; 285:2.

51. Barale C, Frascaroli C, Cavalot F, Guerrasio A, Russo I. In Type 2 Diabetes mellitus the GLP-1 effects on platelets are impaired. Atherosclerosis. 2016; 252:e257-e258.

\section{Figures}




\section{Exenatide-pre}

\section{Exenatide-post}

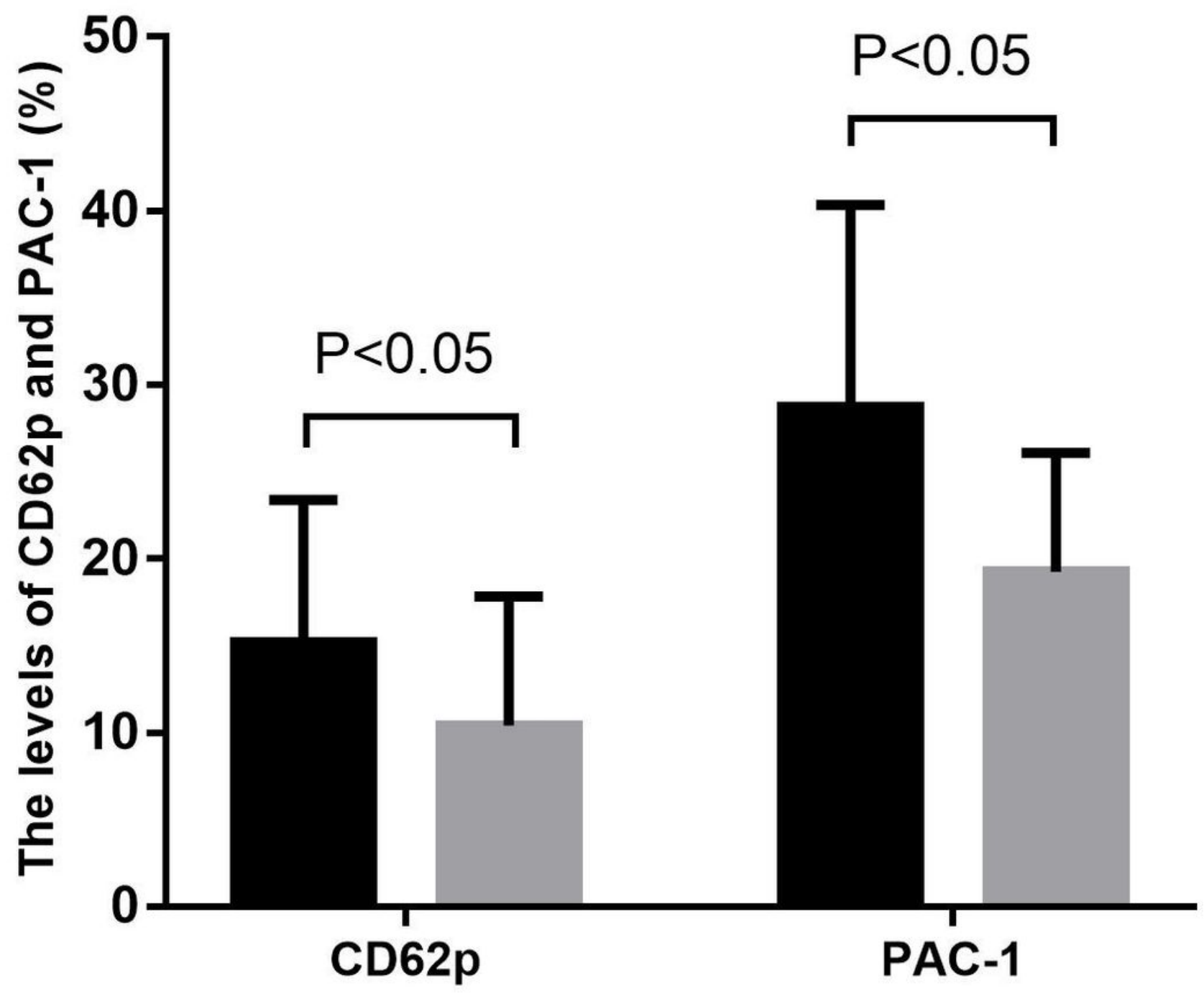

Figure 1

Changes in CD62p and PAC-1 after 8 weeks of exenatide treatment Annotate: platelet activation complex1 


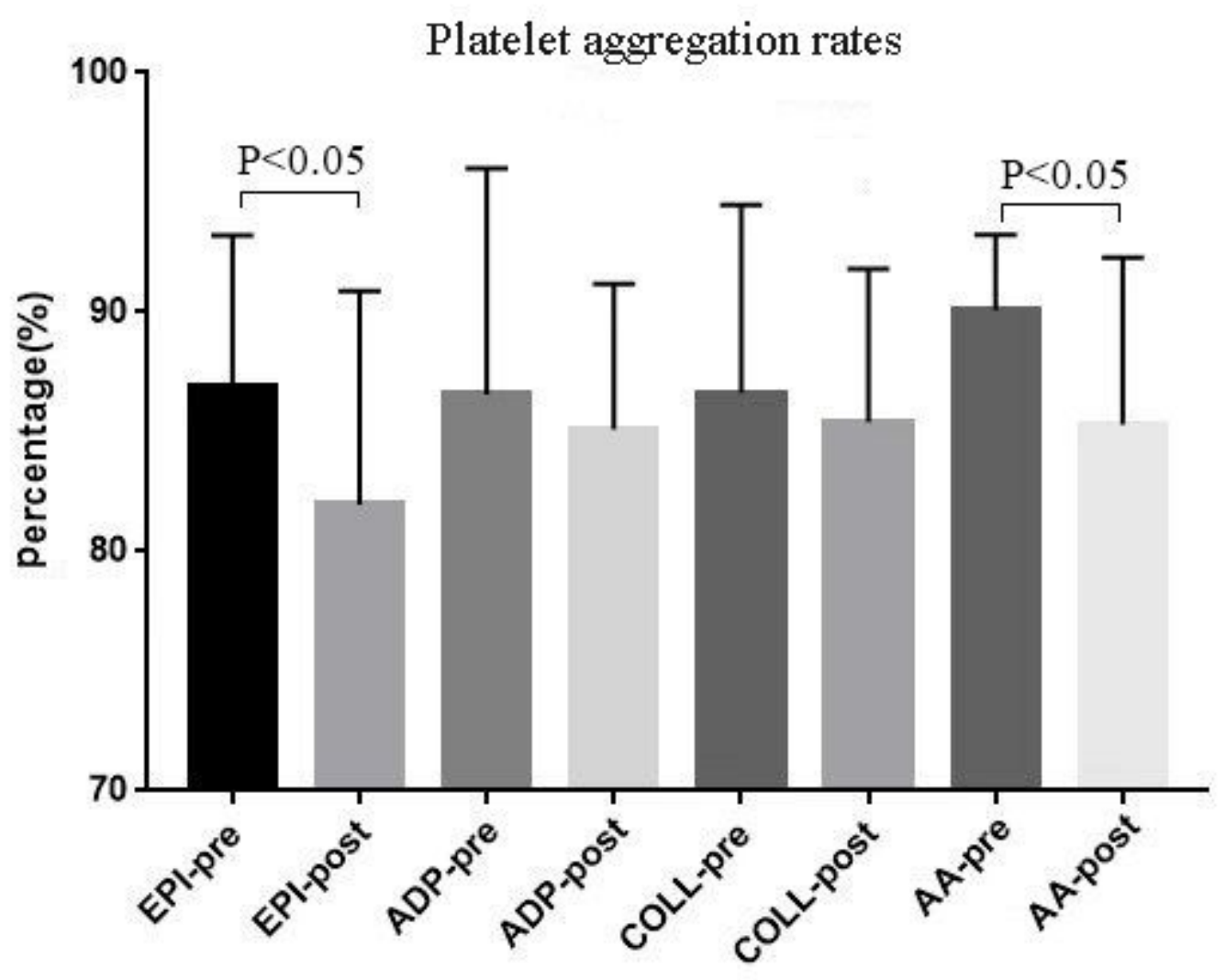

Figure 2

Changes in platelet aggregation rates after 8 weeks of exenatide treatment Annotate: EPI-pre冈platelet aggregation rate before exenatide treatment (epinephrine) $₫ \mathrm{EPI}$-post $₫$ platelet aggregation rate after exenatide treatment (epinephrine) $\triangle A D P$-pre『platelet aggregation rate before exenatide treatment (adenosine diphosphate) $₫$ ADP-post $₫$ platelet aggregation rate after exenatide treatment (adenosine diphosphate) $₫ C O L L-p r e \rrbracket$ platelet aggregation rate before exenatide treatment (collagen) $₫ C O L L-p o s t \rrbracket$ platelet aggregation rate after exenatide treatment (collagen) $₫ A A-p r e \bigotimes$ platelet aggregation rate before exenatide treatment (arachidonic acid) $\triangle A A-$ post $₫$ platelet aggregation rate after exenatide treatment (arachidonic acid). 


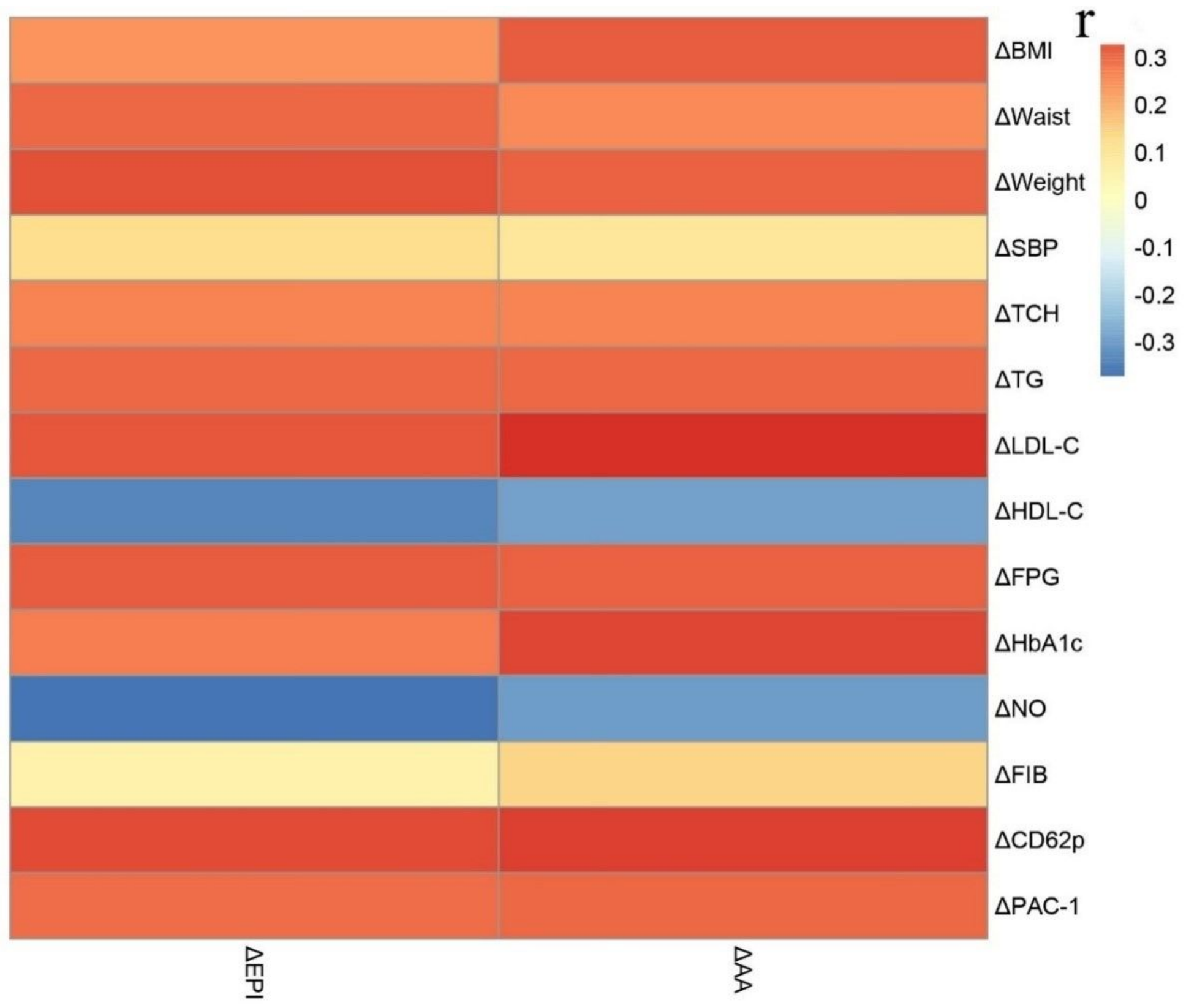

\section{Figure 3}

Correlation between changes in platelet aggregation rates $(\triangle \mathrm{EPI} \triangle \mathrm{AA})$ and changes in other clinical parameters ( $r$ ) Annotate: $\triangle \mathrm{BM} \|$ change in body mass index before and after exenatide treatment $\triangle \triangle \mathrm{SBP}$ : change of systolic blood pressure before and after exenatide treatment $₫ \Delta$ Weight $\varangle$ change in weight before and after exenatide treatment $₫ \Delta$ Waist $₫$ change in waist before and after exenatide treatment $\mathbb{Z}$ $\triangle T C H \rrbracket$ change in total cholesterol before and after exenatide treatment $₫ \Delta T G \llbracket$ change in triglycerides before and after exenatide treatment $\triangle \triangle \mathrm{LDL}-\mathrm{C} \rrbracket$ change in low density lipoprotein cholesterol before and after exenatide treatment $₫ \Delta \mathrm{HDL}-\mathrm{C} \bigotimes$ change in high density lipoprotein cholesterol before and after

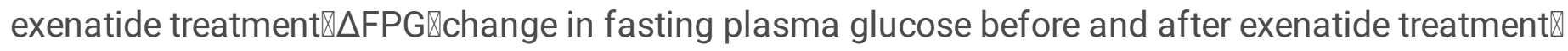
$\triangle \mathrm{HbA} 1 \mathrm{c} \rrbracket$ change in hemoglobin $\mathrm{A} 1 \mathrm{c}$ before and after exenatide treatment $\mathbb{} \Delta \mathrm{NO}$ : change in nitric oxide

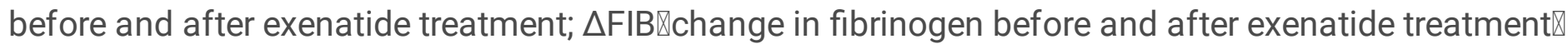
$\triangle$ PAC-1: change in platelet activation complex-1 before and after exenatide treatment $\triangle \triangle \mathrm{EPI} \llbracket \mathrm{changes}$ in 
platelet aggregation rate with epinephrine as inducer before and after exenatide treatment $\triangle \triangle \mathrm{A} A \llbracket \mathrm{changes}$ in platelet aggregation rate with arachidonic acid as inducer before and after exenatide treatment; $r$ : correlation coefficient. 